\title{
Stomatal Opening Mechanism of CAM Plants
}

\author{
Joon Sang Lee
}

Received: 8 January 2010 / Accepted: 11 January 2010 /Published online: 4 February 2010

(C) The Author(s) 2010. This article is published with open access at Springerlink.com

\begin{abstract}
Stomata usually open when leaves are transferred from darkness to light. However, reverse-phase stomatal opening in succulent plants has been known. CAM plants such as cacti and Opuntia ficus-indica achieve their high water use efficiency by opening their stomata during the cool, desert nights and closing them during the hot, dry days. Signal transduction pathway for stomatal opening by blue light photoreceptors including phototropins and the carotenoid pigment zeaxanthin has been suggested. Blue light regulated signal transduction pathway on stomatal opening could not be applied to CAM plants, but the most possible theory for a nocturnal response of stomata in CAM plants is photoperiodic circadian rhythm.
\end{abstract}

Keywords CAM plants · Circadian rhythm ·

Stomatal opening

\section{Stomatal Mechanism of CAM Plants}

Light is the most important environmental factor stimulating stomatal opening. The evidence that light can induce stomatal opening in carbon dioxide concentration comes mainly from studies of the extent of opening in different wavelength of light. Kuiper (1964) action spectrum for opening on epidermal strips of Senico odoris Defl. showed a marked peak in the blue region, substantially higher than that in the red. It is not yet clear how light triggers events

\footnotetext{
J. S. Lee $(\square)$

Department of Biology Education, College of Education, Chungbuk National University,

Cheong Ju,

361-763 ChungBuk, Korea

e-mail: jslee0318@chungbuk.ac.kr
}

which may result in stomatal opening. However, a key achievement on the understanding of stomatal mechanism was the light signal transduction pathway of guard cells. The direct response of stomata to light was initially demonstrated by Heath and Russel (1954) and more recently studied by Zeiger et al. (1987) and Zeiger (1990). They suggested that stomatal response to white light is the combined expression of two distinct photoreceptor systems: guard cell chloroplasts and a blue light-dependent photosystem.

A blue light photoreceptor for the signal transduction chain in guard cells has been suggested to be the carotenoid pigment zeaxanthin (Zeiger et al. 2002; Talbott et al. 2003). Phototropin has also been postulated as a blue light photoreceptor (Kinoshita et al. 2001).

Blue light activates the plasma membrane $\mathrm{H}^{+}$-ATPase via phototropin and creates an intracellular negative electrical potential across the membrane in guard cells (Doi et al. 2006). A number of physiological data have demonstrated that proton efflux originating in guard cells precedes stomatal opening, suggesting that proton efflux is a necessary precursor of stomatal opening (Edwards et al. 1988; Zeiger et al. 1987). Therefore, when stomata open, protons are first pumped out of the guard cell, resulting in a potential gradient across the plasmalemma. This gradient stimulates opening of inward $\mathrm{K}^{+}$channels which may allow $\mathrm{K}^{+}$influx to guard cells resulting in an increase of water potential.

The general appearance of stomata in CAM succulents is largely the same whether they are stem succulents or leaf succulents (Ting 1987). It was observed that the guard cells of Opuntia ficus-indica were slightly sunken below the surface of the leaf and were suspended over large substomatal cavities (Thosom and Journett 1970). Figure 1 shows the characteristic pictures of the stomata of Sedum sarmentosum including chloroplasts in the guard cells (Ahn and Lee, unpublished). Depending on the species, the 


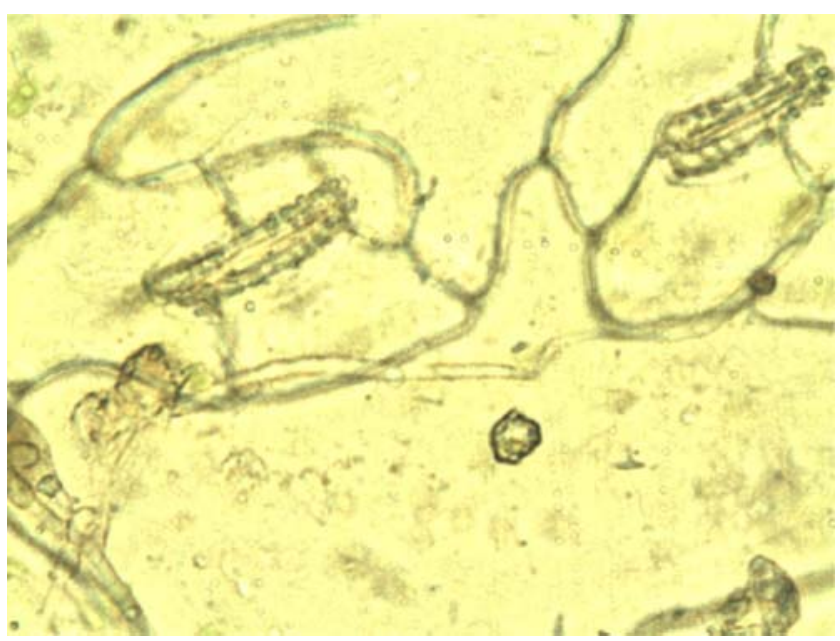

Fig. 1 A micrograph of the stomata of Sedum sarmentosum showing chloroplasts in the guard cells $(\times 1,000)$. The real sizes in microscope were different as the size was edited (Ahn and Lee, unpublished)

structures of stomata are different, and most familiar structures of stomata could be found in Commelina communis and Vicia faba. They have subsidiary cells around guard cells, but those cells could not be found in stomata of Sedum. There is a certain phenomenon representing that the differences of morphological characteristics lead to the different physiological responses even though it could not be applied in all cases.

Bryophyllum daigremontiaum L. opens its stomata during the night as a general pattern of CAM plants. How do CAM plants open their stomata during the night? What is the signal transduction pathway which trigger following events of stomatal opening? It could be estimated that potassium and organic acid play a role in the opening of the stomata of CAM plants as it does in other plants. However, there is some doubt about how CAM plants recognize the night. Meidner and Mansfield (1968) suggested that nocturnal stomatal opening in CAM plants was most likely a normal response to low tissue $\mathrm{CO}_{2}$ concentration. There is an indirect response of stomata to light through the effect of $\mathrm{CO}_{2}$. Scarth (1932) first suggested that light could increase photosynthesis and decrease concentration of $\mathrm{CO}_{2}$ in the intercellular spaces leading to stomatal opening. Morison (1987) suggested that the stomatal response to $\mathrm{CO}_{2}$ is a general phenomenon. Since the intercellular $\mathrm{CO}_{2}$ concentration $\left(c_{\mathrm{i}}\right)$ declines as assimilation increases, and since conductance in many cases increases with decreasing $c_{\mathrm{i}}$, it has been supposed that assimilation controls conductance by effecting changes in $c_{\mathrm{i}}$ (Raschke 1976). However, there is another view that the effect of $c_{\mathrm{i}}$ on stomatal opening is slight (Farquhar et al. 1978; Wong et al. 1978; Morison and Jarvis 1983; Ramos and Hall 1983). Raschke (1975a, 1975b) found that stomata were unresponsive to $\mathrm{CO}_{2}$ in well-watered plants, but $\mathrm{CO}_{2}$ sensitivity of stomata could be increased by abscisic acid (ABA), $\mathrm{Ca}^{2+}$, water stress, and diurnal rhythms. Morison (1987) reported that the tendency for $c_{\mathrm{i}}$ to remain constant after an initial decrease in $c_{\mathrm{i}}$ when stomata start to open in the light.

The $\mathrm{CO}_{2}$ regulation of CAM stomata is an attractive hypothesis because, during the decarboxylation phase of CAM in the light period, internal carbon dioxide reaches a concentration of $1 \%$ or more (Cockburn et al. 1979). The changes in $\mathrm{CO}_{2}$ concentration will be the most possible signal in the initial responses of stomatal opening. The specific and rapid effect of $\mathrm{CO}_{2}$ in stomatal movements could be mediated by changes in membrane permeability, an amplified acidification of guard cell cytoplasm, and a concomitant decrease in the pmf (proton motive force) or the use of $\mathrm{HCO}^{3-}$ as a counter ion for $\mathrm{K}^{+}$(Hsiao 1976; Zeiger et al. 1978; Gepstein et al. 1982; Lee and Bowling 1993). It is a matter of debate that those effects of $\mathrm{CO}_{2}$ in stomatal movements are quite enough to trigger or induce stomatal opening. However, there have been no further great advances on $\mathrm{CO}_{2}$-related signal transduction pathway.

The extensive studies by Querioz and Brulfert (1982) have revealed that CAM is induced by photoperiod in some plants. In Kalanchoe blossfeldiana, for example, short days that induce flowering also induce CAM in young leaves. This induction of CAM is accompanied by the appearance of reverse-phase stomatal opening, consistent with CAM metabolism. It is quite clear that CAM plants open their stomata differently when compared with those of $C$. communis and $V$. faba. The signal transduction chain triggered by a blue light photoreceptor in guard cells could not be applied to the stomatal movement of CAM plants.

Organisms are normally subjected to daily cycles of light and darkness, and plants often exhibit a rhythmic pattern in association with these changes. Examples of such rhythms include leaf and petal movements, and stomatal opening and closing (Taiz and Zeiger 2003). Many cacti and other succulent plants with CAM metabolism open their stomata at night and close them during the day. $\mathrm{CO}_{2}$ is fixed into malate during the night because air temperatures are much lower at night than those of the day. Therefore, water loss is low and a significant amount of water is saved relative to the amount of $\mathrm{CO}_{2}$ fixed. The main constraint on CAM metabolism is that the capacity to store malic acid is limited, and this limitation restricts the amount of $\mathrm{CO}_{2}$ uptake. However, many CAM plants can fix $\mathrm{CO}_{2}$ via the Calvin cycle at the end of the day when temperature gradients are less extreme.

In contrast to $\mathrm{C}_{3}$ and $\mathrm{C}_{4}$ plants, CAM plants open their stomata and fix $\mathrm{CO}_{2}$ at night. The basic role of stomata is to regulate transpiration and photosynthesis. Photosynthesis plays a central role in the physiology of plants and an understanding of its response to light is, therefore, critical in any discussion of how plants sense and respond to light 
(Lee and Bowling 1993). All land plants are faced with competing demands of taking of $\mathrm{CO}_{2}$ from the atmosphere while limiting water loss. In $\mathrm{C}_{3}$ and $\mathrm{C}_{4}$ plants, when water is abundant, the functional solution to this dilemma is the temporal regulation of stomatal apertures' opening during the day and closing at night. At night, when there is no photosynthesis and thus no demand of $\mathrm{CO}_{2}$ inside the leaf, stomatal apertures are kept small, preventing unnecessary loss of water.

In $\mathrm{C}_{3}$ and $\mathrm{C}_{4}$ plants, photorelated signal transduction pathway might be the first step to trigger stomatal opening. Then how CAM plants open their stomata at night? They do not use photoreceptors including phototropins and zeaxanthin in the very first step of stomatal opening as stomata open at night. $\mathrm{CO}_{2}$ might not be the signal to trigger stomatal opening. Wong et al. (1979) found that the diffusive conductance of leaf epidermis to $\mathrm{CO}_{2}$ transfer changed proportionally with the rate of assimilation. Analyses of stomatal response to $\mathrm{CO}_{2}$ and light led to the conclusion that, in most cases, stomata responded to changes in $c_{\mathrm{i}}$ only to a small extent; most of the response to light was 'direct', i.e., not mediated by $\mathrm{CO}_{2}$.

Studies of daily courses of stomatal movements in intact $\mathrm{C}_{3}$ leaves have shown that the potassium content in guard

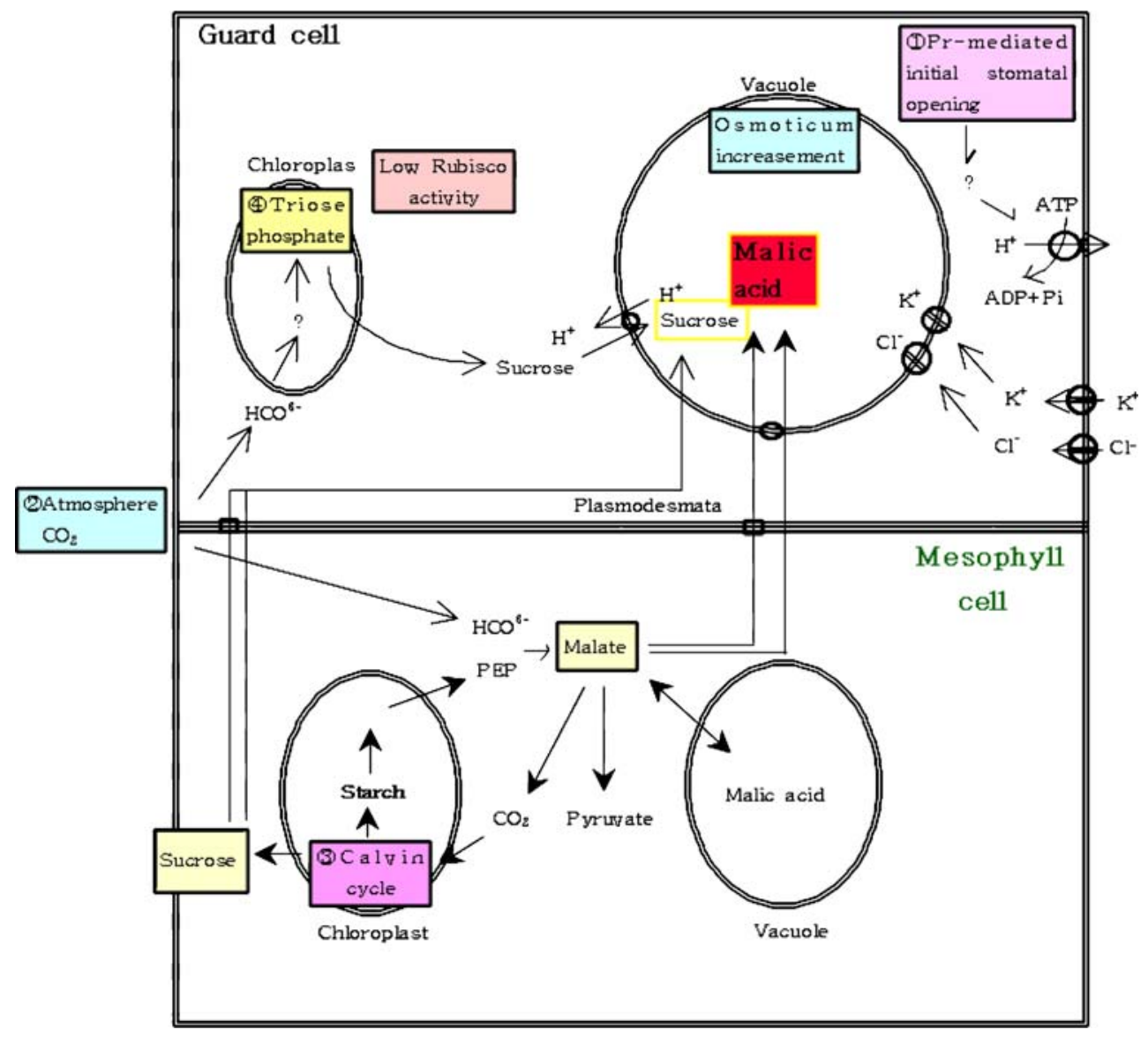

Fig. 2 The possible hypothesis of stomatal opening in CAM plants. A well-described example of a plant circadian rhythm is involved in phytochrome. The initial stomatal opening of CAM plants in darkness could be mediated by phytochrome. (1) Phytochrome regulates membrane potentials and ion fluxes. The plasma membrane $\mathrm{H}^{+}$pump appears to be activated by darkness (provided the phytochrome is in the form of Pfr; Taiz and Zeiger 2003). $\mathrm{K}^{+}$then passively enters the guard cells and some $\mathrm{Cl}^{-}$is also transported, but a complete charge balance of $\mathrm{K}^{+}$is accompanied by the synthesis of malate. (2) $\mathrm{CO}_{2}$ is incorporated via carboxylation of phosphoenolpyruvate to oxalacetate, which is then reduced to malate. The malate accumulates and is stored in the large vacuole of mesophyll cells. Substantial amounts of malate among them will transport to guard cell vacuole through plasmodesmata or across cell wall. Malic acid of vacuole in guard cell will create the requisite turgor pressure which increase or maintain stomatal apertures of CAM plants. (3) The carboxylation of $\mathrm{CO}_{2}$ leads to the net synthesis of glyceraldehyde-3-phosphate (G-3-P) and ribulose 1, 5bisphosphate that regenerates starting materials of the Calvin cycle. Starch and sucrose are synthesized from G-3-P. The synthesis of starch and sucrose are competing processes that occur in the chloroplast and cytosol, respectively. Sucrose transports to vacuole of guard cells through plasmodesmata or across the cell wall. Some recent study results have again suggested that sucrose may play a major role in guard cell osmoregulation in $\mathrm{C}_{3}$ plants. Sucrose could contribute to stomatal opening in CAM plants, but malate will become the dominant osmoticum. (4) Most reports indicate that the photosynthetic carbon reduction pathway is absent in guard cells or, at most, does not exceed about $5 \%$ of that in the mesophyll cells on a chlorophyll basis (Outlaw 1989, 1996) 
cells increases in parallel with early morning opening, but it decreases in the early afternoon under conditions in which apertures continue to increase. The sucrose content of guard cells increases slowly in the morning, but upon potassium efflux, sucrose becomes the dominant osmotically active solute, and stomatal closing at the end of day parallels a decrease in the sucrose content of guard cells (Talbott and Zeiger 1998).

However, in CAM plants, the mechanism of stomatal opening would be quite different.

Firstly, well-characterized signaling pathways in light system on stomatal opening of $\mathrm{C}_{3}$ plants could not be applied to CAM plants. Photoreceptors such as phototropins and zeaxanthin could not trigger stomatal opening.

Secondly, the changes of $\mathrm{CO}_{2}$ concentration inside the leaf could affect stomatal mechanism, but $\mathrm{CO}_{2}$-regulated signal transduction pathway has not been identified. The physiological responses of CAM plants to $\mathrm{CO}_{2}$-enriched atmosphere are less clear since studies are few and, at present, contradictory.

Thirdly, the most possible theory for a nocturnal response of stomata in CAM plants is photoperiodic circadian rhythm.

The period of a rhythm is the time that elapses between successive peaks or troughs in the cycle, and because the rhythm persists in the absence of external controlling factors, it is considered to be endogenous. The endogenous nature of circadian rhythms suggests that they are governed by an internal pace maker. The sleep movements of leaves, referred to as nyctinasty, are well-described examples of a plant circadian rhythm that is regulated by light. In nyctinasty, leaves or leaflets extend horizontally to face the light during the day and fold together vertically at night (Taiz and Zeiger 2003).

Fourthly, in CAM plants, circadian rhythms could be thought of as an opposite response of a nyctinasty.

Fifthly, osmotic materials for the increase of turgor pressure will be $\mathrm{K}^{+}$and sugar such as $\mathrm{C}_{3}$ and $\mathrm{C}_{4}$ plants. It is assumed that potassium plays a role in the opening of the stomata of CAM plant. Dayananda and Kaulfman (1975), studying potassium fluxes and stomatal opening, reported that potassium uptake by guard cells was correlated with stomatal opening in Kalancho and Crassula. A potassiumdominant osmotic increase could be exaggerated as most potassium-related results were obtained by the experiments of epidermal strips that were incubated with potassium solution. Some current studies have again suggested that sucrose may play a major role in guard cell osmoregulation, thus supporting the original theory of starch-sugar involvement (Kim and Lee 2007). Figure 2 shows the possible hypothesis of stomatal opening in CAM plants. Fundamental sources in the increase in osmotic potential required for stomatal opening might be similar with $\mathrm{C}_{3}$ and $\mathrm{C}_{4}$ plants (Fig. 2). However, the initial stomatal opening of CAM plants will depend on the circadian rhythms. Various metabolic processes in plants, such as oxygen evolution and respiration, cycle alternately through high-activity and low-activity phases with a regular periodicity of about $24 \mathrm{~h}$. Light is a strong modulator of rhythms in plants. Although circadian rhythms that persist under controlled laboratory conditions usually have periods one or more hours longer or shorter than $24 \mathrm{~h}$, in nature their periods tend to be uniformly closer to $24 \mathrm{~h}$ because of the synchronizing effects of daybreak, referred to as entrainment. Both red and blue light are effective in entrainment. The red light effect is photoreversible by far-red light, indicative of phytochrome (Taiz and Zeiger 2003).

The essential mechanism of CAM is the acquisition of inorganic carbon by dark fixation of bicarbonate $\left(\mathrm{HCO}^{3-}\right)$ via phosphoenolpyruvate carboxylase. This leads to an organic acid (mainly malic acid)-concentrating effect in the dark period when organic acid is stored in the central cell sap vacuole. In the subsequent light period, organic acid is released from vacuole and again decarboxylated. The $\mathrm{CO}_{2}$ released is fixed by rubisco and converted to carbohydrate by the Calvin cycle. Accordingly, malic acid could be the main osmoticum for the increase of guard cell turgor pressure and the contributions of $\mathrm{K}^{+}$and sugar as osmotic materials might be feeble.

Acknowledgments The author is greatly indebted to professor B. O. Jun at Kangnung National University for his generous review and correction of this paper.

This work was supported by the research grant of the Chungbuk National University in 2008.

Open Access This article is distributed under the terms of the Creative Commons Attribution Noncommercial License which permits any noncommercial use, distribution, and reproduction in any medium, provided the original author(s) and source are credited.

\section{References}

Cockburn W, Ting IP, Stenberg LO (1979) Relationships between stomatal behavior and internal carbon dioxide concentration in crassulcean acid metabolism plants. Plant Physiol 63:1029-1032

Dayananda F, Kaulfman PB (1975) Stomatal movements associated with potassium fluxes. Am J Bot 62:221-231

Doi M, Wada M, Shimazaki E (2006) The fern Adiantum capillusveneris lacks stomatal response to blue light. Plant Cell Physiol 47:748-755

Edwards MC, Smith GN, Bowling DJF (1988) Guard cells extrude protons prior to stomatal opening. J Exp Bot 39:1541-1547

Farquhar GD, Dubbe DR, Rachke K (1978) Gain of the feedback loop involving carbon dioxide and stomata. Plant Physiol 62:406-412

Gepstein S, Jacobs M, Taiz L (1982) Inhibition of stomatal opening in Vicia faba epidermal tissue by vanadate and abscisic acid. Plant Sci Lett 28:63-72

Heath OVS, Russel J (1954) Studies in stomatal behaviour. J Exp Bot $5: 269-292$

Hsiao TC (1976) Stomatal ion transport. In: Luttge UT, Pitman MG (eds) Transport in plants. Springer, Berlin, pp 195-221

Kim DJ, Lee JS (2007) Current theories for mechanism of stomatal opening. Plant J Bio 50(5):523-526 
Kinoshita T, Doi M, Suetsugu N, Kagawa T, Wada M, Shimazaki K (2001) Phot 1 and Phot 2 mediate blue light regulation of stomatal opening. Nature 414:656-660

Kuiper PJC (1964) Dependence upon wavelength of stomatal movement in epidermal tissue of Senecio odoris. Plant Physiol 39:952-955

Lee JS, Bowling DJF (1993) Influence of the mesophyll on the change of electrical potential difference of guard cells induced by red light and $\mathrm{CO}_{2}$ in Commelina communis L. and Trandescantia virginiana L. Korean J Bot 36:383-389

Meidner H, Mansfield TA (1968) Physiology of stomata. McGraw Hill, London

Morison JIL (1987) Intercellular $\mathrm{CO}_{2}$ concentration and stomatal response to $\mathrm{CO}_{2}$. In: Zeiger E, Faquhar GD, Cowan IR (eds) Stomatal function. Stanford University Press, Stanford, CA, pp 229-251

Morison JIL, Jarvis PG (1983) Direct and indirect effects of light on stomata in Commelina communis L. Plant Cell Environ 6:103-109

Outlaw W (1989) Critical examination of the quantitative evidence for and against $\mathrm{CO}_{2}$ fixation by guard cells. Physiol Plant 77:275-281

Outlaw W (1996) Stomata: biophysical and biochemical aspects. In: Baker NR (ed) Photosynthesis and the environment. Kluwer, Dordrecht, pp 241-259

Querioz O, Brulfert J (1982) Photoperiod-controlled induction and enhancement of stomatal adaptation to drought. In: Ting IP, Gibbs M (eds) Crassulacean acid metabolism. American Soc Phyto, pp 208-230

Ramos C, Hall AE (1983) Effects of photon fluorescence rate and intercellular partial $\mathrm{CO}_{2}$ pressure on leaf conductance and $\mathrm{CO}_{2}$ uptake rate in Capsicum and Amarantus. Photosynthetica 17:34-42

Raschke K (1975a) Simultaneous requirement of carbon dioxide and abscisic acid for stomatal closing in Xanthium strumarium L. Planta 125:243-259

Raschke K (1975b) Stomatal action. Ann Rev Plant Physiol 26:309-340
Raschke K (1976) How stomata resolve the dilemma of opposing priorities. Phyll Trans R Soc Lond 273:551-560

Scarth GW (1932) Mechanism of action of light and other factors on stomatal movement. Plant Physiol 7:481-504

Talbott LD, Zeiger E (1998) The role of sucrose in guard cell osmoregulation. J Exp Bot 49:329-337

Talbott LD, Shimayevich IJ, Chung Y, Hammad JW, Zeiger E (2003) Blue light and phytochrome-mediated stomatal opening the npq1 and phot1 phot2 mutants of Arabidopsis. Plant Physiol 133:15221529

Taiz L, Zeiger E (2003) Plant physiology, 3rd edn. Sinauer Associates, Sunderland

Thosom WW, Journett RD (1970) Studies of ultrastructure of the guard cells of Opuntia. Am J Bot 57:309-316

Ting IP (1987) Stomata in plants with crassulacean acid metabolism. In: Zeiger E, Faquhar GD, Cowan IR (eds) Stomatal function. Stanford University Press, Stanford, CA, pp 353-366

Wong SC, Cowan IR, Farquhar GD (1978) Leaf conductance in relation to assimilation in Eucalyptus pauciflora Sieb. ex Spreng. Plant Physiol 62:670-674

Wong SC, Cowan IR, Farquhar GD (1979) Stomatal conductance correlates with photosynthetic capacity. Nature 282:424-426

Zeiger E (1990) Light perception in guard cells. Plant Cell Environ 13:739-747

Zeiger E, Bloom AJ, Hepler PK (1978) Ion transport in stomatal guard cells. What's new. Plant Physiol 9:29-32

Zeiger E, Iino MM, Shimazaki K, Ogawa T (1987) The blue light response of stomata. In: Zeiger E, Faquhar GD, Cowan IR (eds) Stomatal function. Stanford University Press, Stanford, CA, pp 209-227

Zeiger E, Talbott LD, Frechilla S, Srivastava A, Zhu J (2002) The guard cell chloroplast: a perspective for the twenty-first century. New Phyto 153:415-424 